\title{
Efficacy and Safety of Paclitaxel Combined With Cetuximab for Head and Neck Squamous Cell Carcinoma
}

\author{
TAKURO OKADA, ISAKU OKAMOTO, HIROKI SATO, TATSUYA ITO, \\ KEITARO MIYAKE and KIYOAKI TSUKAHARA \\ Department of Otorhinolaryngology and Head and Neck Surgery, \\ Tokyo Medical University, Tokyo, Japan
}

\begin{abstract}
Background/Aim: For recurrent/metastatic squamous cell carcinoma of the head and neck (R/M SCCHN), popular regimens containing platinum-based anticancer agents and immune checkpoint inhibitors are impractical for platinum-intolerant patients. Herein, the efficacy and safety of paclitaxel and cetuximab combination therapy in R/M SCCHN were evaluated. Patients and Methods: In this retrospective study, paclitaxel $\left(80 \mathrm{mg} / \mathrm{m}^{2}\right)$ and cetuximab $\left(400 \mathrm{mg} / \mathrm{m}^{2}\right.$ loading dose followed by $250 \mathrm{mg} / \mathrm{m}^{2}$ weekly) were administered in 28-day cycles on days 1, 8, and 15. Results: Thirty-eight patients were treated. The overall response and disease control rates of first-line therapy were $43 \%$ and $79 \%$, respectively, while those of second-line and later therapies were $20 \%$ and $90 \%$, respectively. The median progression-free and overall survival were 5.3 and 12.5 months, respectively. All adverse events were manageable, including grade 3/4 neutropenia and anaemia affecting $8-13 \%$ of patients. Conclusion: Paclitaxel and cetuximab combination therapy may be suitable for treating R/M SCCHN.
\end{abstract}

Recurrent/metastatic squamous cell carcinoma of the head and neck (R/M SCCHN) has a poor prognosis, and the overall survival is usually around one year (1). It is treated with systemic chemotherapy, and extreme regimens (5fluorouracil+cisplatin/carboplatin+cetuximab) with platinumbased anticancer agents as the key drugs have long been considered as first choice for treatment (2). Additionally, immune checkpoint inhibitors (ICIs) have been widely used

This article is freely accessible online.

Correspondence to: Isaku Okamoto, MD, Ph.D., Department of Otorhinolaryngology Head and Neck Surgery, Tokyo Medical University, 6-7-1 Nishishinjuku, Shinjuku-ku, Tokyo 160-0023, Japan. Tel: +81 333426111, Fax: +81 333469275, e-mail: isaku@tokyo-med.ac.jp

Key Words: Paclitaxel, cetuximab, head and neck, squamous cell carcinoma. for head and neck cancer. However, the response rate of ICIs is not particularly high, and the time taken to manifest efficacy is a shortcoming. Therefore, cytotoxic anticancer agents are often used instead of ICIs in patients with pain, other subjective symptoms, and/or rapidly growing tumours.

In a phase II trial of weekly paclitaxel and cetuximab in platinum-refractory R/M SCCHN, high efficacy was reported (3). Moreover, several real-world retrospective studies on this combination as first-line therapy in patients who failed platinum-based therapy have reported an ORR, median PFS, and median OS of 45-52\%, 6.0-7.7 months, and 10.0-16.8 months, respectively (4-7).

At our Institution, we typically administer combination therapy of paclitaxel and cetuximab for platinum-refractory or intolerant R/M SCCHN, and the objective of this study was to retrospectively examine its usefulness in this regard.

\section{Patients and Methods}

Patients. The target population included 51 patients who received paclitaxel and cetuximab combination therapy for R/M SCCHN at Tokyo Medical University Hospital from January 2014 to October 2019. Among 48 patients with squamous cell carcinoma, 10 were excluded because target lesions could not be evaluated by imaging, leaving 38 as subjects (Figure 1).

This study received approval from the ethics committee (approval no. T2020-0028) and was conducted according to the Declaration of Helsinki.

Staging methods. TNM classification was performed according to the criteria postulated by the Union for International Cancer Control (8).

Treatment and follow-up. Dosing was performed by following a 28 day cycle in which paclitaxel and cetuximab were administered on days 1,8 , and 15 . Paclitaxel was infused at $80 \mathrm{mg} / \mathrm{m}^{2}$ over $1 \mathrm{~h}$. Cetuximab was infused over $2 \mathrm{~h}$ at $400 \mathrm{mg} / \mathrm{m}^{2}$ for the first dose and $250 \mathrm{mg} / \mathrm{m}^{2}$ from the second dose onwards. Target lesions were evaluated every 2-3 months using computed tomography or magnetic resonance imaging. Treatment was continued until the disease progressed, intolerable adverse effects appeared, or the attending physician deemed discontinuation necessary for other reasons. No dose reduction criteria were established. 


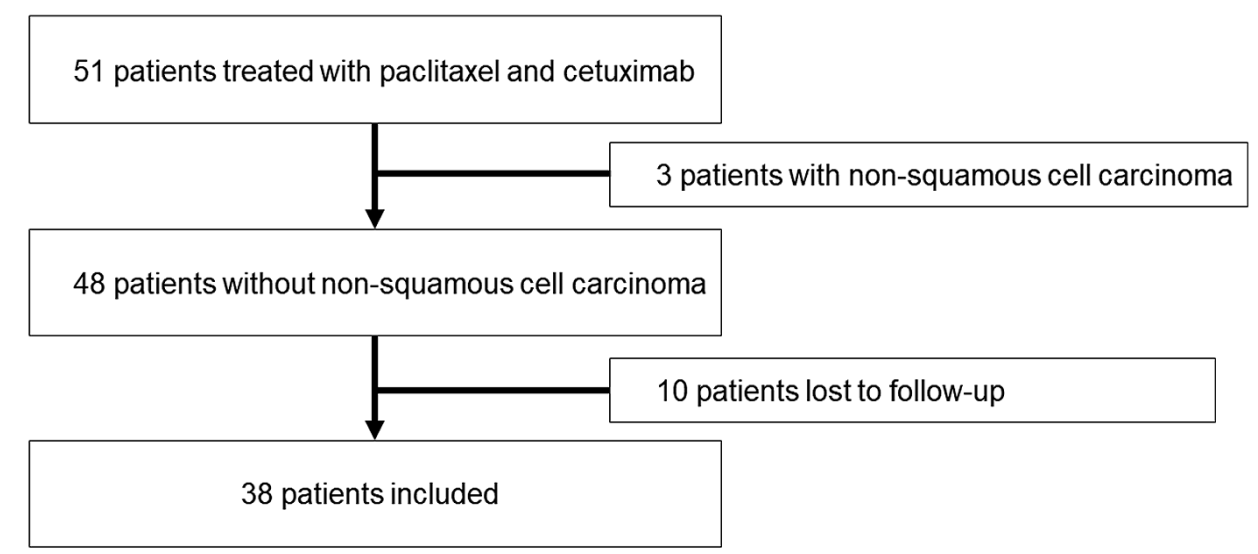

Figure 1. Flowchart outlining the selection of study subjects.

Endpoint. The primary endpoint was ORR [complete response (CR) + partial response $(\mathrm{PR})]$. The secondary endpoints were disease control rate (DCR) $[\mathrm{CR}+\mathrm{PR}+$ stable disease (SD)], PFS, OS, and adverse events (AEs). AEs were evaluated using the Common Terminology Criteria for Adverse Events version 4.0 (9). PFS was defined as the period from the start of administration to disease progression or death, while OS was the period from the start of administration to death or the date of final follow-up. For ORR, target lesions were evaluated using RECIST version 1.1, and ORR was determined as the best overall response (BOR) (10).

PFS and OS were compared between first-line therapies and second-line and later therapies. For patients receiving second-line and later therapies, PFS and OS were compared between those with and without prior nivolumab therapy. PFS and OS were also compared between platinum-sensitive and platinum-refractory patients. Platinum-refractory carcinoma was defined as recurrence or tumour enlargement within 6 months of starting platinum-based anticancer drugs, while platinum-sensitivity referred to recurrence or tumour enlargement after 6 months.

Statistical analysis. PFS and OS were calculated using the KaplanMeier method and analysed using the log-rank test. The survival period was analysed according to a Cox proportional hazards model, and $p<0.05$ was considered statistically significant.

All statistical analyses were performed with EZR (Saitama Medical Center, Jichi Medical University, Saitama, Japan), a graphical user interface for R (The R Foundation for Statistical Computing, Vienna, Austria) (11).

\section{Results}

Clinical characteristics. The patient clinical characteristics are shown in Table I. There were 33 men and 5 women with a median age of 65 years (range $=28-78$ years).

The median number of doses administered was 13 for paclitaxel (range=5-144), and 13 for cetuximab (range=5144). There were $28(74 \%), 6(16 \%)$, and $4(11 \%)$ patients receiving first-line, second-line, and third-line therapies, respectively. Nine patients had received nivolumab previously. Thirty patients had received platinum anticancer agents, 15 of whom were platinum-refractory and 15 were platinum-sensitive (Table II).

Efficacy. The best treatment outcomes are shown in Table III. The ORR and DCR were 37\% and 82\% (5 CR, 9 PR, and 17 SD), respectively. For first-line therapy, the ORR and DCR were $43 \%$ and $79 \%$ (4 CR, 8 PR, and $10 \mathrm{SD}$ ), respectively, while for second-line and later therapies, they were $20 \%$ and 90\% (1 CR, 1 PR, and 7 SD), respectively. The median PFS and median OS were 5.3 months $(95 \% \mathrm{CI}=3.9-9.8)$ and 12.5 months (95\% CI=8.4-17.8), respectively (Figure 2). With a median PFS of 6.2 months for first-line therapy, survival was significantly prolonged compared to 3.4 months for secondline and later therapies $(\mathrm{HR}=2.46 ; 95 \% \mathrm{CI}=1.01-6.00$; $p=0.049$ ). Median OS for first-line therapy was 15.3 months which was not significantly different from 12.1 months $(\mathrm{HR}=1.65 ; 95 \% \mathrm{CI}=0.62-4.41 ; p=0.32)$ for second-line and later therapies (Figure 3).

Among the 10 patients who received second-line and later therapies, 9 received nivolumab prior and exhibited ORR, DCR, median PFS, and median OS of $22 \%$ (1 CR and $1 \mathrm{PR}$ ), $89 \%$ (CR, PR, and 6 SD), 4.1 months, and 12.1 months, respectively. Considering prior nivolumab use, the median PFS for patients who did not previously receive nivolumab was 6.2 months and those who did was 4.1 months; however, the difference was not significant $(\mathrm{HR}=2.13$; 95\% $\mathrm{CI}=0.85$ 5.33; $p=0.11)$. Furthermore, the median OS for patients without and with prior nivolumab use was 12.5 months and 12.1 months, respectively; this difference was not significant either $(\mathrm{HR}=1.51 ; 95 \% \mathrm{CI}=0.53-4.23 ; p=0.44)$. Similarly, the difference between the median PFS for platinum-refractory carcinoma (6.2 months) and that for platinum-sensitive carcinoma (4.4 months) was not significant ( $\mathrm{HR}=1.33 ; 95 \%$ $\mathrm{CI}=0.55-3.21 ; p=0.53)$. At 12.5 months, the median $\mathrm{OS}$ for 
Table I. Patient clinical characteristics.

\begin{tabular}{|c|c|c|}
\hline & $\begin{array}{l}\text { Number of } \\
\text { patients }(\mathrm{N})\end{array}$ & $\begin{array}{c}\text { Percentage } \\
(\%)\end{array}$ \\
\hline Total & 38 & 100 \\
\hline \multicolumn{3}{|l|}{ Age } \\
\hline Median (years) & 65 & \\
\hline Range (years) & $28-78$ & \\
\hline \multicolumn{3}{|l|}{ Gender } \\
\hline Male & 33 & 86.8 \\
\hline Female & 5 & 13.2 \\
\hline \multicolumn{3}{|l|}{ ECOG performance status } \\
\hline 0 & 35 & 92.1 \\
\hline 1 & 3 & 7.9 \\
\hline \multicolumn{3}{|l|}{ Primary site } \\
\hline Oral cavity & 3 & 8.0 \\
\hline Nasopharynx & 2 & 5.2 \\
\hline Oropharynx & 16 & 42.1 \\
\hline p16+ & 5 & \\
\hline p16- & 2 & \\
\hline Unknown & 9 & \\
\hline Hypopharynx & 10 & 68.4 \\
\hline Larynx & 3 & 8.0 \\
\hline Paranasal cavity & 1 & 2.63 \\
\hline External ear & 1 & 2.6 \\
\hline Unknown & 2 & 5.3 \\
\hline \multicolumn{3}{|l|}{ Initial therapy } \\
\hline Surgery & 18 & 47.4 \\
\hline Radiation & 29 & 76.3 \\
\hline \multicolumn{3}{|l|}{ Target lesion } \\
\hline Locoregional & 11 & 29.0 \\
\hline Distant & 18 & 47.4 \\
\hline Locoregional + distant & 9 & 23.7 \\
\hline \multicolumn{3}{|l|}{ Platinum } \\
\hline Refractory & 15 & 39.5 \\
\hline Sensitive & 15 & 39.5 \\
\hline Not used & 8 & 21.1 \\
\hline
\end{tabular}

ECOG, Eastern cooperative oncology group.

platinum-refractory carcinoma was not significantly different from that for platinum-sensitive carcinoma at 14.0 months $(\mathrm{HR}=0.91 ; 95 \% \mathrm{CI}=0.36-2.26 ; p=0.84)$.

Safety. The AEs are shown in Table IV. Among the 3 patients with interstitial pneumonia, cetuximab was discontinued in 2 patients with grade 3 pneumonia and administration was continued with paclitaxel alone. There were no grade 5 AEs.

\section{Discussion}

In this study, the ORR and DCR of paclitaxel and cetuximab combination chemotherapy for R/M SCCHN were $37 \%$ and $82 \%$, respectively. Median PFS and median OS were 5.3 months and 12.5 months, respectively. The PFS of first-line therapy was significantly prolonged compared to that of
Table II. Summary of treatment.

\begin{tabular}{lcc}
\hline & $\mathrm{N}$ & Percentage (\%) \\
\hline $\begin{array}{l}\text { Number of PTX doses } \\
\text { Median (range) }\end{array}$ & $13(5-144)$ & \\
Number of Cmab doses & $13(5-144)$ & \\
$\quad$ Median (range) & 28 & \\
Administration line & 6 & 73.7 \\
$1^{\text {st }}$ & 4 & 15.8 \\
$2^{\text {nd }}$ & 9 & 10.5 \\
$3^{\text {rd }}$ & & 23.7 \\
Prior nivolumab use & \\
\hline
\end{tabular}

PTX, Paclitaxel; Cmab, cetuximab.

second-line and later therapies. There was no significant difference in survival rate between patients with and without prior nivolumab use or between platinum-sensitive and platinum-refractory patients. Moreover, AEs could mostly be controlled. Those of grade 3 and above with a high prevalence were leukocytopenia (18\%) and anaemia (13\%), but none were life-threatening.

Previous studies on paclitaxel and cetuximab combination chemotherapy in R/M SCCHN are shown in Table V (3-7, 12-15). For first-line therapy, ORR and DCR were $45-54 \%$ and $67-83 \%$, respectively, and for second-line therapy, they were $38-71 \%$ and $74-100 \%$, respectively, consistent with the results of $37 \%$ and $82 \%$, respectively, in the present study. The first-line therapy significantly prolonged PFS over second-line and later therapies, indicating the advisability of initiating early administration.

Re-administration of platinum-based agents is more effective for platinum-sensitive than platinum-refractory carcinoma, and the regimen varies depending on the period from the start of platinum administration to recurrence (16, 17). Based on the CheckMate 141 and Keynote 048 trials, the recommended drugs for platinum-refractory and platinumsensitive R/M SCCHN are nivolumab and extreme regimens involving pembrolizumab plus (5-fluorouracil and cisplatin/carboplatin), respectively $(18,19)$. However, in patients with pain and other subjective symptoms or with rapidly expanding tumours, we cannot expect ICIs to be effective because the response rate is not very high and their effects manifest only after some time. As paclitaxel and cetuximab combination chemotherapy showed good efficacy in patients irrespective of whether they were platinumrefractory or -sensitive, we considered it effective in these patients regardless of the duration of platinum administration.

Conversely, chemotherapy after nivolumab improves OS relative to best supportive care, demonstrating its usefulness after ICI administration (20). In patients who received sequential chemotherapy after ICI, 53\% received taxane plus 
A Progression-free survival

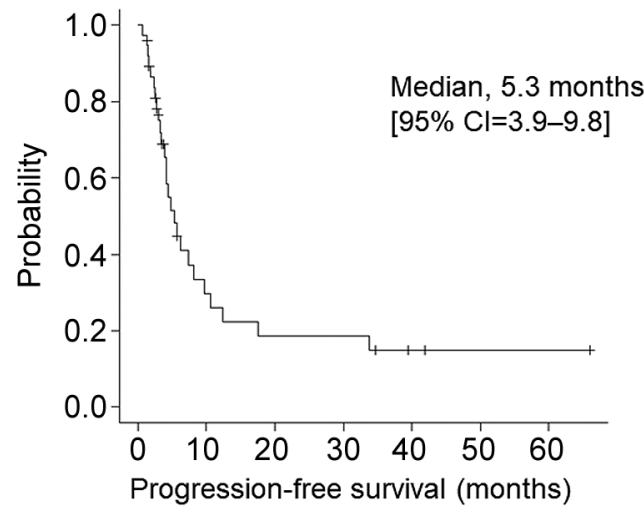

B Overall survival

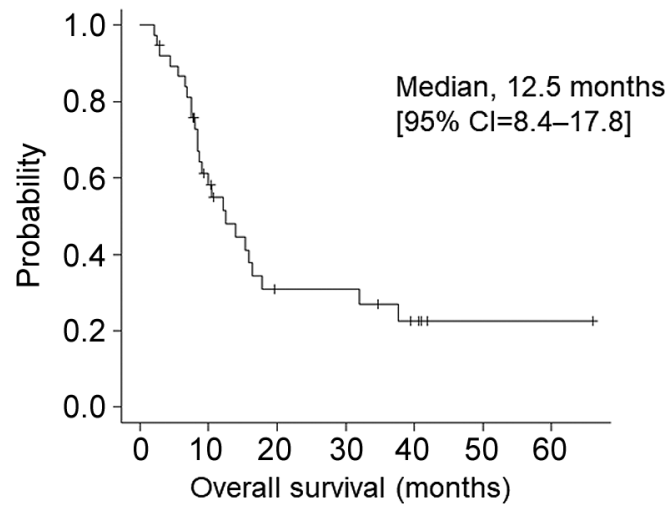

Figure 2. Kaplan-Meier plots (A) progression-free survival and (B) overall survival.

Table III. Tumour responses.

\begin{tabular}{|c|c|c|c|c|c|c|c|c|}
\hline & \multicolumn{2}{|c|}{ All patients } & \multicolumn{2}{|c|}{ First-line therapy } & \multicolumn{2}{|c|}{ Second-line therapy } & \multicolumn{2}{|c|}{ Prior nivolumab use } \\
\hline & $\mathrm{N}$ & $\%$ & $\mathrm{~N}$ & $\%$ & $\mathrm{~N}$ & $\%$ & $\mathrm{~N}$ & $\%$ \\
\hline Best overall response & 38 & & 28 & & 10 & & 9 & \\
\hline Complete response & 5 & 13.2 & 4 & 14.3 & 1 & 10.0 & 1 & 11.1 \\
\hline Partial response & 9 & 23.7 & 8 & 28.6 & 1 & 10.0 & 1 & 11.1 \\
\hline Stable disease & 17 & 44.7 & 10 & 35.7 & 7 & 70.0 & 6 & 66.7 \\
\hline Progressive disease & 7 & 18.4 & 6 & 21.4 & 1 & 10.0 & 1 & 11.1 \\
\hline Overall response rate & 14 & 36.8 & 12 & 42.9 & 2 & 20.0 & 2 & 22.2 \\
\hline Disease control rate & 31 & 81.6 & 22 & 78.6 & 9 & 90.0 & 7 & 88.9 \\
\hline
\end{tabular}

Overall response rate $=$ complete response $(C R)+$ partial response $(P R)$. Disease control rate $=C R+P R+$ stable disease $(\mathrm{SD})$.

cetuximab plus platinum which resulted in an ORR of $30 \%$ and DCR $57 \%$ (21). In the 9 patients with prior nivolumab use in this study, DCR being $89 \%$ and median OS 12.1 months were favourable, indicating the usefulness of paclitaxel and cetuximab as sequential chemotherapy. Thus, the response rate for paclitaxel and cetuximab combination chemotherapy for both first-line and second-line therapies was high. According to the National Comprehensive Cancer Network (NCCN) guidelines, platinum, nivolumab, and pembrolizumab have a higher priority in the treatment of R/M SCCHN (22). Additionally, although they provide details for paclitaxel alone and cetuximab alone, there are none for combination therapy. Nevertheless, the combination therapy achieved good results for second-line and later therapies, which were comparable to those for first-line therapy. As it could be used as sequential chemotherapy after ICI and would not be influenced by whether patients were platinum-refractory or -sensitive, we believe that the
Table IV. Summary of adverse events.

\begin{tabular}{lrrrr}
\hline & \multicolumn{2}{c}{ All grades } & \multicolumn{2}{c}{ Grade 3-4 } \\
\cline { 2 - 5 } & $\mathrm{N}$ & $\%$ & $\mathrm{~N}$ & $\%$ \\
\hline $\begin{array}{l}\text { Haematologic adverse events } \\
\text { Leukocytopenia }\end{array}$ & 22 & 57.9 & 7 & 18.4 \\
$\quad$ Neutropenia & 16 & 42.1 & 3 & 7.9 \\
$\quad$ Anaemia & 29 & 76.3 & 5 & 13.2 \\
Non-haematologic adverse events & & & & \\
$\quad$ Acne-like rash & 20 & 52.6 & 1 & 2.6 \\
Paronychia & 10 & 26.3 & 1 & 2.6 \\
Interstitial pneumonia & 3 & 7.9 & 2 & 5.3 \\
Peripheral neuropathy & 13 & 34.2 & 1 & 2.6 \\
AST increase & 1 & 2.6 & 0 & 0 \\
ALT increase & 1 & 2.6 & 0 & 0 \\
Hyponatremia & 4 & 10.5 & 0 & 0 \\
Hypokalaemia & 2 & 5.3 & 0 & 0 \\
Hypomagnesemia & 18 & 47.4 & 1 & 2.6 \\
\hline
\end{tabular}

AST, Aspartate aminotransferase; ALT, alanine aminotransferase. 


\section{A Progression-free survival}

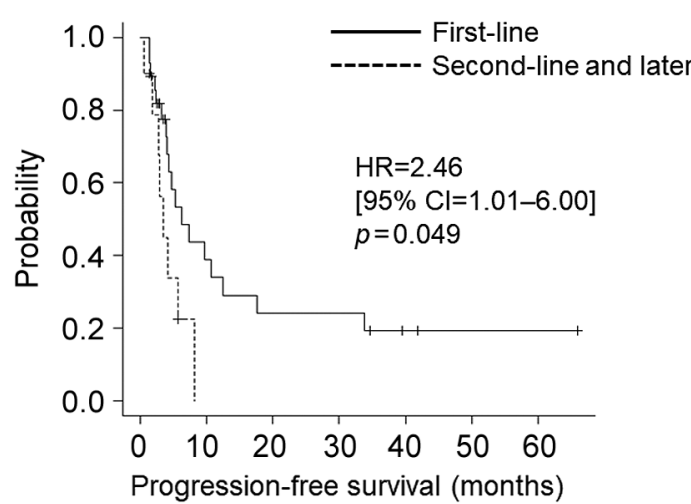

B Overall survival

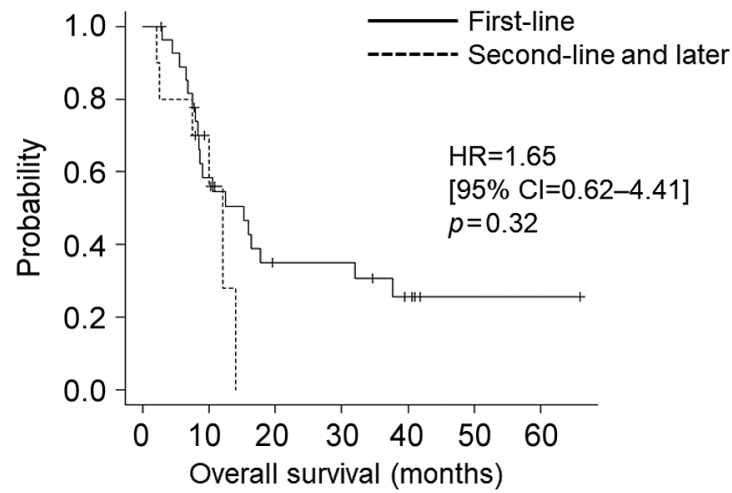

Figure 3. Kaplan-Meier survival curves of comparison of administration line.

Table V. Summary of literature reports on paclitaxel and cetuximab for squamous cell carcinoma of head and neck.

\begin{tabular}{|c|c|c|c|c|c|c|c|c|c|c|c|c|c|c|c|}
\hline \multirow{3}{*}{ Authors } & \multirow{3}{*}{$\begin{array}{c}\text { Year of } \\
\text { publication }\end{array}$} & \multicolumn{4}{|c|}{ First-line } & \multicolumn{6}{|c|}{ Second-line } & \multicolumn{2}{|c|}{ All grades } & \multicolumn{2}{|c|}{ Grade $3 / 4$} \\
\hline & & n & ORR & DCR & $\begin{array}{c}\text { Median } \\
\text { PFS }\end{array}$ & $\begin{array}{l}\text { Median } \\
\text { OS }\end{array}$ & $\mathrm{n}$ & ORR & DCR & $\begin{array}{l}\text { Median } \\
\text { PFS }\end{array}$ & $\begin{array}{l}\text { Median } \\
\text { OS }\end{array}$ & $\begin{array}{l}\text { Acne- } \\
\text { like rash }\end{array}$ & Neuropathy & $\begin{array}{l}\text { Acne- } \\
\text { like rash }\end{array}$ & Neutropenia \\
\hline & & & $\%$ & $\%$ & Months & Months & & $\%$ & $\%$ & Months & Months & $\%$ & $\%$ & $\%$ & $\%$ \\
\hline Hitt et al. (3) & 2012 & 46 & 54 & 80 & 4.2 & 8.1 & - & - & - & - & - & 88 & - & 24 & 13 \\
\hline Bernad et al. (4)* & 2017 & 117 & 47 & 67 & 7.0 & 10.0 & 31 & - & - & - & - & - & - & - & - \\
\hline Enokida et al. (5) & 2018 & 23 & 52 & 83 & 7.0 & 16.3 & - & - & - & - & - & 67 & 74 & 13 & 13 \\
\hline Nakano et al. (6) & 2017 & 49 & 45 & - & 6.0 & 16.8 & - & - & - & - & - & - & - & 6 & 12 \\
\hline Pellini et al. (7) & 2017 & 59 & 48 & 78 & 7.7 & 13.2 & - & - & - & - & - & 58 & 22 & - & 3 \\
\hline Sosa et al. (12) & 2014 & - & - & - & - & - & 33 & 55 & 79 & 4.0 & 10.0 & 100 & 12 & 3 & - \\
\hline Péron et al. (13) & 2012 & - & - & - & - & - & 42 & 38 & 74 & 3.9 & 7.6 & - & 24 & $12^{* *}$ & 7 \\
\hline Jiménez et al. (14) & 2013 & - & - & - & - & - & 20 & 55 & - & 5.2 & 9.1 & 70 & $15^{* *}$ & 4 & - \\
\hline Wakasaki et al. (15) & 2019 & - & - & - & - & - & 7 & 71 & 100 & - & - & - & - & - & - \\
\hline This study & & 28 & 43 & 79 & 6.2 & 15.3 & 10 & 20 & 90 & 3.4 & 12.1 & 53 & 34 & 3 & 8 \\
\hline
\end{tabular}

ORR, Overall response rate; DCR, disease control rate; PFS, progression-free survival; OS, overall survival. *ORR, DCR, PFS, and OS are combinations of first-line and second-line therapy. **Grade 2 and higher.

paclitaxel and cetuximab combination chemotherapy would be useful in any treatment situation.

Peripheral neuropathy, a characteristic adverse event of paclitaxel and acne-like rash, a characteristic adverse event of cetuximab, could be factors that reduce the quality of life. At $3 \%$, the prevalence of grade 3 or above peripheral neuropathy and acne-like rash was low and controllable. Because paclitaxel and cetuximab combination chemotherapy is palliative, AEs should be minimized. The package insert of paclitaxel distributed in Japan recommends six weeks of administration followed by a 2 -week rest period (23). Considering this, in the present study, paclitaxel was administered not on a weekly basis, but with three doses and one rest period to reduce AEs. The prevalence of AEs was lower than that reported in the literature and helped improve the quality of life. The complete absence of discontinuation, a maintained response rate, and a low prevalence of adverse events can be comprehensively evaluated.

Photoimmunotherapy is one of the latest therapies for treating R/M SCCHN. A phase I/IIa study of photoimmunotherapy on R/M SCCHN (RM-1929-101) was conducted in 2015. Based on these results, it was fasttracked in the US in January 2018. This therapy is based on cetuximab sarotalocan sodium, an antibodyphotosensitive substance complex consisting of cetuximab [anti-human epidermal growth factor receptor (EGFR) monoclonal antibody] bound to IR700 dye, a photosensitive substance. The antibody-photosensitive substance complex 
is believed to selectively bind to EGFRs expressed by cancer cells. When the tumour is irradiated with nearinfrared rays through excitation, IR700 causes a photochemical reaction, which rapidly destroys cancer cell membranes, leading to necrosis (24). In patients responsive to cetuximab and paclitaxel combination chemotherapy, photoimmunotherapy could be effective because anti-EFGR antibodies would be bound to cancer cells. In the future, we hope that evidence will be accumulated using a large sample size.

The advantage of paclitaxel and cetuximab combination chemotherapy was that it had a high response rate in both first and second line. Therefore, in R/M SCCHN, a therapeutic effect can be expected regardless of platinum refractory or platinum sensitivity. In addition, adverse events were controllable and could contribute to the maintenance of quality of life.

This study has several limitations. First, as it was a retrospective study using treatment records, selection bias was unavoidable. The choice of chemotherapy regimen was influenced by the overall body condition and prior therapy. Second, not all patients administered ICI at our Institution were analysed. Third, in Japan, not all the drugs recommended in the NCCN guidelines can be used, making a simple comparison with studies from other countries difficult. However, in view of the high DCR and low incidence of AEs, paclitaxel and cetuximab combination chemotherapy is considered a treatment option following ICI therapy for patients who are platinum-refractory or platinumintolerant, those with subjective symptoms, and those with rapidly growing tumours.

\section{Conclusion}

In this retrospective study, the usefulness of paclitaxel and cetuximab combination chemotherapy in both platinumsensitive and platinum-refractory R/M SCCHN was demonstrated. It showed particular promise as a sequential chemotherapy following ICI therapy.

\section{Conflicts of Interest}

The Authors declare no conflicts of interest.

\section{Authors' Contributions}

TO designed this study. TO and IO contributed to collection and interpretation of the data. TO, IO, HS, TI, KM, and KT contributed to data collection and patient management. TO was a major contributor in writing the manuscript.

\section{Acknowledgements}

The Authors would like to thank Editage (www.editage.com) for English language editing.

\section{References}

1 León X, Hitt R, Constenla M, Rocca A, Stupp R, Kovács AF, Amellal N, Bessa EH and Bourhis J: A retrospective analysis of the outcome of patients with recurrent and/or metastatic squamous cell carcinoma of the head and neck refractory to a platinum-based chemotherapy. Clin Oncol (R Coll Radiol) 17(6): 418-424, 2005. PMID: 16149284. DOI: 10.1016/j.clon.2005.02.014

2 Vermorken JB, Mesia R, Rivera F, Remenar E, Kawecki A, Rottey S, Erfan J, Zabolotnyy D, Kienzer HR, Cupissol D, Peyrade F, Benasso M, Vynnychenko I, De Raucourt D, Bokemeyer C, Schueler A, Amellal N and Hitt R: Platinumbased chemotherapy plus cetuximab in head and neck cancer. N Engl J Med 359(11): 1116-1127, 2008. PMID: 18784101. DOI: 10.1056/NEJMoa0802656

3 Hitt R, Irigoyen A, Cortes-Funes H, Grau JJ, García-Sáenz JA, Cruz-Hernandez JJ and Spanish Head and Neck Cancer Cooperative Group (TTCC): Phase II study of the combination of cetuximab and weekly paclitaxel in the first-line treatment of patients with recurrent and/or metastatic squamous cell carcinoma of head and neck. Ann Oncol 23(4): 1016-1022, 2012. PMID: 21865152. DOI: $10.1093 /$ annonc/mdr367

4 Bernad IP, Trufero JM, Urquizu LC, Pazo Cid RA, de Miguel AC, Agustin MJ, Lanzuela M and Antón A: Activity of weekly paclitaxel-cetuximab chemotherapy in unselected patients with recurrent/metastatic head and neck squamous cell carcinoma: prognostic factors. Clin Transl Oncol 19(6): 769-776, 2017. PMID: 28120324. DOI: 10.1007/s12094-016-1604-z

5 Enokida T, Okano S, Fujisawa T, Ueda Y, Uozumi S and Tahara M: Paclitaxel plus cetuximab as $1^{\text {st }}$ line chemotherapy in platinum-based chemoradiotherapy-refractory patients with squamous cell carcinoma of the head and neck. Front Oncol 8: 339, 2018. PMID: 30211118. DOI: 10.3389/fonc.2018.00339

6 Nakano K, Marshall S, Taira S, Sato Y, Tomomatsu J, Sasaki T, Shimbashi W, Fukushima H, Yonekawa H, Mitani H, Kawabata $\mathrm{K}$ and Takahashi S: A comparison of weekly paclitaxel and cetuximab with the EXTREME regimen in the treatment of recurrent/metastatic squamous cell head and neck carcinoma. Oral Oncol 73: 21-26, 2017. PMID: 28939072. DOI: 10.1016/ j.oraloncology.2017.07.022

7 Pellini Ferreira B, Redman M, Baker KK, Martins R, Eaton KD, Chow LQM, Baik CS, Goulart B, Lee SM, Santana-Davila R and Rodriguez CP: Predictors of outcome with cetuximab and paclitaxel for head and neck squamous cell carcinoma. Laryngoscope 127(7): 1583-1588, 2017. PMID: 27905113. DOI: 10.1002/lary.26422

8 Sobin LH, Gospodarowicz MK and Wittekind C; International Union against Cancer: TNM classification of malignant tumours. Chichester, West Sussex, UK; Hoboken, NJ: Wiley-Blackwell, 2010 .

9 Common Terminology Criteria for Adverse Events (CTCAE) v.3.0 and v.4.0. National Cancer Institute, 2006 and 2010. Available at: https://ctep.cancer.gov/protocolDevelopment/electronic_applicatio ns/ctc.htm [Last accessed on 28th December 2020]

10 Eisenhauer EA, Therasse P, Bogaerts J, Schwartz LH, Sargent D, Ford R, Dancey J, Arbuck S, Gwyther S, Mooney M, Rubinstein L, Shankar L, Dodd L, Kaplan R, Lacombe D and Verweij J: New response evaluation criteria in solid tumours: revised RECIST guideline (version 1.1). Eur J Cancer 45(2): 228-247, 2009. PMID: 19097774. DOI: 10.1016/j.ejca.2008.10.026 
11 Kanda Y. Investigation of the freely available easy-to-use software 'EZR' for medical statistics. Bone Marrow Transplant 48(3): 452458, 2013. PMID: 23208313. DOI: 10.1038/bmt.2012.244

12 Sosa AE, Grau JJ, Feliz L, Pereira V, Alcaraz D, Muñoz-García $\mathrm{C}$ and Caballero M: Outcome of patients treated with palliative weekly paclitaxel plus cetuximab in recurrent head and neck cancer after failure of platinum-based therapy. Eur Arch Otorhinolaryngol 271(2): 373-378, 2014. PMID: 23644939. DOI: $10.1007 / \mathrm{s} 00405-013-2537-6$

13 Péron J, Ceruse P, Lavergne E, Buiret G, Pham BN, Chabaud S, Favier B, Girodet D, Zrounba P, Ramade A and Fayette J: Paclitaxel and cetuximab combination efficiency after the failure of a platinum-based chemotherapy in recurrent/metastatic head and neck squamous cell carcinoma. Anticancer Drugs 23(9): 996-1001, 2012. PMID: 22643048. DOI: 10.1097/CAD.0b013e32835507e5

14 Jiménez B, Trigo JM, Pajares BI, Sáez MI, Quero C, Navarro V, Llácer C, Medina L, Rueda A and Alba E: Efficacy and safety of weekly paclitaxel combined with cetuximab in the treatment of pretreated recurrent/metastatic head and neck cancer patients. Oral Oncol 49(2): 182-185, 2013. PMID: 23026069. DOI: 10.1016/j.oraloncology.2012.09.003

15 Wakasaki T, Yasumatsu R, Uchi R, Taura M, Matsuo M, Komune $\mathrm{N}$ and Nakagawa $\mathrm{T}$ : Outcome of chemotherapy following nivolumab treatment for recurrent and/or metastatic head and neck squamous cell carcinoma. Auris Nasus Larynx 47(1): 116-122, 2020. PMID: 31128940. DOI: 10.1016/j.anl.2019.05.001

16 Sano D, Fujisawa T, Tokuhisa M, Shimizu M, Sakagami T, Hatano T, Nishimura G, Ichikawa Y, Iwai H and Oridate N: Real-world treatment outcomes of the EXTREME regimen as first-line therapy for recurrent/metastatic squamous cell carcinoma of the head and neck: a multi-center retrospective cohort study in Japan. Anticancer Res 39(12): 6819-6827, 2019. PMID: 31810948. DOI: 10.21873/anticanres.13898

17 Sato H, Tsukahara K, Okamoto I, Katsube Y, Shimizu A, Kondo T, Hanyu K, Fushimi C, Okada T and Miura K: Clinical outcomes of platinum-based chemotherapy plus cetuximab for recurrent or metastatic squamous cell carcinoma of the head and neck: comparison between platinum-sensitive and platinumresistant patients. Acta Otolaryngol 139(2): 201-205, 2019. PMID: 30794080. DOI: 10.1080/00016489.2018.1551623

18 Ferris RL, Blumenschein G Jr, Fayette J, Guigay J, Colevas AD, Licitra L, Harrington K, Kasper S, Vokes EE, Even C, Worden F, Saba NF, Iglesias Docampo LC, Haddad R, Rordorf T, Kiyota N, Tahara M, Monga M, Lynch M, Geese WJ, Kopit J, Shaw JW and Gillison ML: Nivolumab for recurrent squamous-cell carcinoma of the head and neck. N Engl J Med 375(19): 18561867, 2016. PMID: 27718784. DOI: 10.1056/NEJMoa1602252
19 Burtness B, Harrington KJ, Greil R, Soulières D, Tahara M, de Castro G, Jr., Psyrri A, Basté N, Neupane P, Bratland Å, Fuereder T, Hughes BGM, Mesía R, Ngamphaiboon N, Rordorf T, Wan Ishak WZ, Hong RL, González Mendoza R, Roy A, Zhang Y, Gumuscu B, Cheng JD, Jin F and Rischin D; KEYNOTE-048 Investigators: Pembrolizumab alone or with chemotherapy versus cetuximab with chemotherapy for recurrent or metastatic squamous cell carcinoma of the head and neck (KEYNOTE-048): a randomised, open-label, phase 3 study. Lancet 394(10212): 1915-1928, 2019. PMID: 31679945. DOI: 10.1016/S0140-6736(19)32591-7

20 Fushimi C, Okamoto I, Matsuki T, Masubuchi T, Okada T, Sato H, Tsukahara K, Kondo T, Yamashita T, Hanyu K, Omura GO, Takahashi H, Tada Y and Miura K: Salvage chemotherapy after nivolumab for recurrent or metastatic head and neck carcinoma. Anticancer Res 40(9): 5277-5283, 2020. PMID: 32878817. DOI: 10.21873/anticanres. 14532

21 Saleh K, Daste A, Martin N, Pons-Tostivint E, Auperin A, Herrera-Gomez RG, Baste-Rotllan N, Bidault F, Guigay J, Le Tourneau C, Saada-Bouzid E and Even C: Response to salvage chemotherapy after progression on immune checkpoint inhibitors in patients with recurrent and/or metastatic squamous cell carcinoma of the head and neck. Eur J Cancer 121: 123-129, 2019. PMID: 31574417 . DOI: 10.1016/j.ejca.2019.08.026

22 National Comprehensive Cancer Network: NCCN clinical practice guidelines in oncology, Head and Neck Cancers (version 1, 2021). Available at: https://www.nccn.org/professionals/ physician_gls/pdf/head-and-neck.pdf [Last accessed on 28th January 2021]

23 Bristol-Myers Squibb: Drug information sheet for paclitaxel. Date of publication: February 2018. Available at: http://file.bmshealthcare.jp/bmshealthcare/pdf/package/TX1802. pdf [Last accessed on 28th December 2020]

24 Mitsunaga M, Ogawa M, Kosaka N, Rosenblum LT, Choyke PL and Kobayashi H: Cancer cell-selective in vivo near infrared photoimmunotherapy targeting specific membrane molecules. Nat Med 17(12): 1685-1691, 2011. PMID: 22057348. DOI: $10.1038 / \mathrm{nm} .2554$
Received January 6, 2021

Revised January 27, 2021

Accepted January 28, 2021 